\title{
Is Anyone Listening? Audience Engagement through Public Media Related to the Scottish Independence Referendum
}

\author{
Irati Agirreazkuenaga-Onaindia, Ainara Larrondo-Ureta and Simón Peña-Fernández *(D) \\ Department of Journalism II, School of Social and Communication Sciences, University of the Basque, \\ 48940 Lejona, Vizcaya, Spain \\ * Correspondence: simon.pena@ehu.eus
}

Received: 20 June 2019; Accepted: 13 August 2019; Published: 23 August 2019

\begin{abstract}
This paper explores perspectives from which citizen participation in media debates on civic issues can be reconsidered by means of a review of the existing literature on this subject and a qualitative study of how one particular public service media programme facilitated audience engagement and involvement in public discussion leading up to a major political event. The first section provides a general discussion of what media organisations do to engage the public they serve on political and social issues, the challenge of stimulating audience involvement and the ways in which editors and producers attempt to give average citizens a voice on topics normally framed by elites. The second offers a case study based on semi-structured interviews and content analysis of public participation in Morning Call, a weekday British Broadcasting Corporation (BBC) Radio Scotland phone-in news and current affairs show (the only programme of its type broadcast in Scotland) during the run-up to the 2014 Scottish independence referendum. Focus has been placed on determining what programmes of this nature can and cannot achieve in terms of civic engagement and which practices implemented by public broadcasting networks best stimulate audience engagement.
\end{abstract}

Keywords: participation; public media; BBC Scotland; phone-ins; Scottish independence referendum

\section{Introduction}

This paper focuses on the capacity of public media to foster civic involvement and political engagement. It parts from the premise that that citizens become active and critical agents who use technology as an element for political decision making (Blumler and Kavanagh 2000), and that meaningful citizen participation in public debate is only possible in circumstances in which co-production takes place, which is to say in settings that establish a power-sharing relationship between media organisations and the audiences they serve (Carpentier 2014).

As Lewis (2012) points out, the culture spawned by digital media must also be regarded as a new social environment in which audiences and users are empowered and motivated to create and distribute their own content. But, on the other hand, the reluctance of mainstream media in Western countries to foster public engagement on topics of political importance is undoubtedly linked to their interest in protecting their privileged role as gatekeepers of information (Witschge 2014). Thus, despite the fact that, in general, online media enable spaces for users to provide content that they themselves have created, they are rarely allowed to participate in the selection and filtering process (Steensen 2011). This concern is shared by political actors, who fear criticism and who also wish to control political communication (Macnamara et al. 2012). Although private and public broadcasters both offer programmes allowing audiences to express their opinions, they almost invariably retain editorial control over the discussion of any topic addressed. Broadcast media take a minimalist rather 
than a maximalist approach to audience interaction that permits them to determine what topics are open for discussion and to control what content gets aired (Carpentier 2012). Therefore, any serious conversation about power sharing needs to be framed within a context in which audiences take part in setting the agenda. Couldry, Livingstone and Markham, who have examined this subject at length, (Couldry et al. 2007) have noted that media consumption contributes to people's sense of 'public connection', that the better part of the population of the UK feels in some way connected to the larger public debate on issues of societal importance and that this connection is mediated. This being the case, what are the social media and audience managers of public service broadcasting networks doing to give citizens a voice in public debate?

Although major mainstream commercial and public radio and television networks use audience participation as a means of boosting engagement, they take care to ensure that such interaction does not challenge their power to shape public opinion. While retaining the right to have the final say about what gets aired is one way to control broadcast discourse, the practice of limiting audience participation to soft topics is highly effective as well. It is simply a matter of encouraging audiences to contribute to conversations about sports, fashion, cooking and gardening and addressing political issues in other formats that offer little or no opportunity for audiences to express their opinions. In their case study of public service media in Austria, Grünangerl et al. (2012, p. 27) note that public broadcasting services in that country provide access to target groups such as minorities as legally required. They nevertheless characterise the content-related interaction these broadcasters maintain with audiences as being limited to certain types of programs and insufficiently inclusive and consider public participation in Austrian PSB programming decisions to date to have been negligible.

These authors underscore the link between media participation and political engagement at a moment when civic participation in the political process is reaching unprecedented lows throughout Europe. In countries where elections have traditionally been viewed as opportunities for citizens to renew their commitment to society and bring about needed change, political abstention signifies a profound failure of faith in the democratic process. The low participation in many of the new channels enabled, especially in social networks, do not seem to mobilize the disenchanted electorate (Prior 2007; Warner et al. 2012). Given the current circumstances, what can the media do to raise the political awareness and engagement of the audiences they serve? While the range of options open to public broadcasting services for fostering audience participation may be limited, there is no reason to assume that viewers and listeners should not be given a voice or be confined to merely symbolic roles. This study was conducted on the premise that while the notion that power can be fully shared may be a utopian proposition, major public media outlets are attempting to reach broader audiences and engage them on socially and politically relevant issues.

\section{Research Goals and Context}

This paper raises a series of questions regarding the possibility of recasting the current discourse on citizen participation in the media in the context of the role played by public service broadcasters in facilitating audience engagement and involvement during major political processes. The primary mission of all public service media is to disseminate information and foster dialogue (Moe 2008). Although the Internet and the digital communications channels it has given rise to have opened up new opportunities for citizen interaction and participation in public affairs, public service broadcasters are generally expected to do more than maintain an online presence (Livingstone 2004). Interaction, in particular, must be fully integrated into TV and radio content and newsroom practices, because, as Dahlgren (2005) points out, there must be a structural connection between these communication spaces and the decision-making processes. Because, to be encouraged to participate, audiences must perceive that they are being heard.

The main objective of this study was to demonstrate that even though the media have yet to develop power-sharing relationships with their audiences, they nevertheless have mechanisms at their disposal for generating meaningful audience engagement in specific circumstances. 
To this end, this study has focused on one public radio programme's efforts to facilitate citizen participation in public debate surrounding the 2014 Scottish independence referendum. Of particular interest to researchers was what this type of programme can and cannot achieve in terms of fostering public connection in the context of a highly politicised issue on which mediated discussion has a major bearing. This article begins with an analysis of the quality and characteristics of Scottish television, radio and press coverage of the referendum process conducted from a research and journalistic perspective before exploring how debate on the referendum unfolded on Morning Call, a live weekday phone-in radio show broadcast by British Broadcasting Corporation (BBC) Scotland that holds the distinction of being the only media programme in that country to have offered average citizens the opportunity to express their opinions on the subject.

This case study will document one particular radio programme's efforts to engage its listeners on political and social issues, discuss the complexities of fostering audience participation and analyse what the editors and producers involved have done to encourage ordinary citizens to weigh in on topics normally framed exclusively by elites.

As explained at greater length in the methodology section, research was conducted on site in Scotland between February and September 2014, a period during which the debate on Scottish independence reached its height. It had been established on the basis of negotiations between the governments in Edinburgh and in Westminster and the recommendations of the Electoral Commission (an independent body that oversees elections in the UK) that voters should be asked to respond to a single question: Should Scotland be an independent country? The call for a popular vote on this question, first articulated by Scottish National Party leader Alex Salmon, stemmed from the desire of a significant percentage of Scottish citizens for sovereignty in areas of governance still administered from London such as tax collection, unemployment benefits, health care and broadcasting services. Much of the debate leading up to the referendum centred on the economic strength of Scotland, defence arrangements, Scotland's post-independence relations with the rest of the UK and its future membership in supranational organisations (particularly the European Union).

Various studies have been carried out on the role of the media during this referendum, both on the legacy media (Blain and Hutchinson 2016; Dekavalla 2016; Wayne 2016) and social media (Shephard and Quinlan 2015; Lachlan 2016). A brief examination of media consumption in the UK and Scotland from the perspective of the types of media and topics consumed as well as the public's understanding of the basic structures and dynamics of UK politics at various levels helps to put the objectives and methods of this study into context. To begin with, over one-half (59\%) of the people participating in a 2012 survey conducted in the UK considered television to be an impartial news source. The same respondents regarded the BBC to be the most impartial of the various broadcasting networks serving the UK. Radio was seen as the second most impartial news medium (52\%), followed by broadcasting services websites (29\%), newspapers (24\%), newspaper websites (20\%) and other websites (19\%). Public trust in the impartiality of television and radio in the UK slumped between 2010 and 2012 . Whereas $66 \%$ of citizens polled in 2010 considered them impartial, only $57 \%$ held that opinion in 2012 (Ofcom 2013).

Television is far and away the preferred news source in all of the nations that make up the UK. Although $78 \%$ of the Scottish population follows the news via television, Scots are less likely than people living elsewhere in the UK to consider the BBC their primary news source $(44 \%$ versus an average of $53 \%$ for the UK as a whole). Moreover, Scotland is the only nation within the UK in which newspapers rank among the five most popular sources of news content (Ofcom 2013). The top three newspapers in Scotland are The Scottish Sun (the Scottish edition of a highly popular UK red-top tabloid that has a circulation of 271,953), the Daily Record (a Scottish red-top tabloid with a circulation of 234,313) and the Scottish Daily Mail (the Scottish edition of a UK tabloid that has a circulation of 99,304). Two newspapers with lower circulations known for their quality journalism are The Herald (a Scottish broadsheet with a circulation of 43,157) and The Scotsman (a Scottish broadsheet with a circulation of 32,435). 
A comparison of this data to statistics published in the 2012 and 2013 editions of the Hansard Society's Audit of Political Engagement in Britain provides a rough idea of the extent to which Scottish citizens are actively interested in political issues. Broadsheet readers (74\%) professed a greater interest in politics than red-top readers (37\%) in 2013. Germane to the topic of the research reported here, almost three-quarters of the people surveyed for the Hansard Society study (72\%) thought that referendums should be used more often to determine important questions. A breakdown of attitudes by type of reader (broadsheet 77\%, red-top 75\% and local newspaper readers $76 \%$ ) indicates that a broad consensus exists on this issue. While practically all of the participants in this study interested in politics were keen on following current events as well, almost one-half (47\%) of those who indicated an interest in current events described themselves as "not very" or "not at all" interested in politics. The latter group was slightly more inclined to read tabloid news than other segments of the survey population: $38 \%$ expressed an interest in this kind of newspaper compared to an average of $32 \%$ for the survey population as a whole. Although a lower than average percentage of respondents in this group stated a desire to be involved in national decision making, (35\% compared to the across-the-board average of $42 \%$ ), they expressed about the same level of interest in local affairs as others. Such statistics would appear to indicate that it is clearly better for people to read some kind of newspaper than to read no newspaper at all: those who do not are less inclined to hold strong views one way or the other, less interested in politics, know less about how government works and are much less likely to vote. The Hansard Society findings provide little evidence that red-top newspapers stimulate political engagement on the part of their readers.

\subsection{Parliament and Public Survey Data}

Only 27\% of the people surveyed for the Hansard Society's 2013 Audit of Political Engagement felt fairly or very satisfied with "the way that [the UK] Parliament works". A greater number of survey respondents (37\%) felt that they knew "a fair amount" about the institution but only one out of two understood "that government and Parliament are not the same thing" and a lower 19\% agreed with the statement "Parliament is working for me". Approximately one-half (47\%) "wished they had learned more about politics and democracy in school".

It would thus appear that British media are not doing everything they could to foster political awareness and engagement in the UK. According to the Hansard Society's Connecting Citizens to Parliament report (Hansard Society 2013) "the mainstream media fails to reach a number of different groups as a result of low levels of parliamentary coverage on television, radio and in newspapers (of which circulation is decreasing) and a negative perception of television coverage (and political reporting in general)". The authors of this document nevertheless stress the importance of the role the media play in improving public knowledge of how the British Parliament functions and suggest that Parliament make a stronger effort to connect with citizens via these outlets (Hansard Society 2011, p. 51).

\subsection{The Audit of Political Engagement: The Media and Politics}

An overwhelming majority of the people surveyed for the Hansard Society's 2012 Audit of Political Engagement (75\%) stated that television was their main source of political news and information. A lesser number relied on tabloid newspapers (27\%), radio (26\%), news websites (20\%), broadsheet newspapers (16\%) and social media (6\%) for the same kind of content (Hansard Society 2012).

Almost three-quarters (74\%) of tabloid readers believed that their newspapers "are more interested in getting a story than telling the truth". Over one-half (55\%) thought television was more apt than other media to "help the public to learn about what is happening in politics", and $41 \%$ believed that television networks were "generally fair in their representation of politicians" (41\%). Respondents thought broadsheet newspapers provided better coverage of politics than tabloids but believed that television reporting on political affairs was even better (pp. 3-4). The Hansard Society's 2012 audit concluded that British media (particularly the printed press, and even more specifically tabloids) are 
not fostering the civic political engagement essential to the democratic process and that most British citizens feel that newspapers do a poor job of informing and educating their readers and fail to hold politicians and government to account.

Returning to the particular role that television plays in informing the public, it is important to remember that television and radio continue to be the most popular forms of media in Scotland. Although the BBC attracts a larger audience than Scotland's private television network Scottish Television (STV), according to a 2013 survey (BBC Trust 2014), Scottish viewers are less satisfied with the way the BBC represents "their life in news and current affairs content" than viewers in other parts of the UK. Only $48 \%$ (slightly below the average of $54 \%$ for the rest of the UK) "feel represented" in news, drama and entertainment broadcast by the BBC (idem).

Only 50\% of the Scottish participants in a survey conducted between January and February 2013 by NatCen Social Research (2013) for the BBC Trust (the governing body of the BBC) considered the $\mathrm{BBC}$ licence fee to be good value for money, compared to $58 \%$ of viewers residing elsewhere the UK. The relative disenchantment in Scotland with what the BBC offered viewers there in 2013 may well have been at least partially attributable to the relative dearth of regional representation in programming mentioned in a report released five years earlier by the Scottish Broadcasting Commission (2008), which seconded industry regulator Ofcom's call for measures to address "the emerging gap that Scotland represents in the plurality of the UK's public service broadcasting system".

The BBC's handling of the independence debate drew sharp public criticism from journalists and academics, many of whom considered the network's coverage of the referendum to be biased and incomplete. Although the referendum was scheduled to take place on 18 September 2014, the BBC waited until the end of 2013 to recruit the extra journalists it needed to cover the event. The network provided special coverage in various media formats, most notably television, a prime example of which was The Referendum Debate, a bi-monthly show devoted entirely to the topic. However, its traditional news programmes such as Newsnight came under public fire for taking an excessively conservative approach to the issue (Paterson 2014).

In February 2014, Edinburgh University professor Robertson (2014) published a report on "phase 1" television coverage of the referendum campaign in which he asserted that news programmes broadcast by Scotland's two principal television networks (the BBC and STV) had both taken an unbalanced, partisan approach to the topic. This study, which analysed twelve months of programming, revealed that UK-wide channels offered far less coverage of the independence debate than Scottish channels between September 2012 and September 2013, a striking fact given the constitutional challenge to the integrity of the UK the independence movement supposed. It also noted that reporting provided by BBC Scotland and STV during this initial stage of the referendum campaign contained a disproportionally high ratio $(3: 2)$ of anti-independence to pro-independence statements and tended to personalise political issues.

\section{Methodology and Case Study}

This paper provides an overview of the circumstances under which the British and Scottish media covered the 2014 Scottish independence referendum followed by a case study of a BBC Scotland radio phone-in programme that explores how public media can engage audiences on difficult issues by raising these topics in a non-elitist, accessible atmosphere that fosters interaction. The greater part of the data analysed was obtained by means of qualitative research techniques.

The first phase of research involved a review of existing literature on audience participation, the ways in which BBC journalists have incorporated user-generated content into programmes (Williams et al. 2011), strategies employed to foster audience participation in political talk shows (Ross 2004) and previous studies focused specifically on the media's role in public debate leading up to the Scottish independence referendum. Following this initial groundwork, the authors conducted semi-structured interviews with two freelance journalists who had covered the referendum for Scottish and British newspapers of record. One was Gerry Hassan, currently Senior Research Fellow in contemporary 
Scottish history at Dundee University, who held the positions of Senior Research Fellow at the Institute for Public Policy Research Scotland and Research Fellow in cultural policy at the University of the West of Scotland at the time he was interviewed for this study. Hassan is the author of Caledonian Dreaming: The Quest for a Different Scotland (Hassan 2014), a book on Scottish identity released to great acclaim in 2014, as well as numerous articles on topics and issues related to Scotland published by newspapers of record in Scotland and the UK such as The Scotsman, The Herald, Holyrood, Sunday Mail and The Guardian. The other person interviewed was Peter Geoghegan, an Irish freelance investigative journalist and writer based in Glasgow whose latest book, The People's Referendum: Why Scotland Will Never Be the Same Again (Geoghegan 2014), was nominated for the Saltire Society First Book Prize. Geoghegan, who has written for a range of publications and news sites including in The Guardian, The Times Literary Supplement, The Scotsman, The Irish Times, RTE, The Independent, Al Jazeera and The Dublin Review, has also made radio documentaries for various networks and channels including BBC Radio 4.

The next step entailed active listening sessions of Morning Call, a three-hour-long daily morning phone-in show produced by BBC Radio Scotland that had the largest audience of any programme in its time slot at the time of this study. In February and June 2014, researchers conducted on-site observation sessions at the BBC Radio Scotland studios where the show is produced and subsequently performed a thorough content analysis of three episodes. A crucial aspect of the observational research carried out was an in-depth interview with the BBC Radio Scotland's Editor of Topical Programmes and Events Colin Paterson, during which the interviewee provided a general overview of phone-in programmes and audience participation for Radio Scotland and key information about how Morning Call handled the sensitive nature of current affairs in June 2014. All empirical data was collected between February and December 2014, the peak period of the referendum media campaigns.

As previously mentioned, analysis focused on a time-honoured radio format designed to stimulate meaningful listener engagement by means of live calls from listeners. Morning Call invites listeners from all over Scotland to participate in live weekday morning discussions of news and current affairs. The show prides itself on its record of getting to the heart of issues of public interest and offering listeners an opportunity to have their say.

Phone-in shows have a reputation of being lowbrow. Although numerous studies have been conducted on talk show radio (Hutchby 2013), Morning Call 's unique status as the only interactive programme of its type in Scotland and its role at a crucial juncture in contemporary Scottish history make it a compelling research object. In the course of this exploration, we will argue that by virtue of the daily interactions it fostered with listeners, this programme was perfectly positioned to take on a completely new significance as a forum for public discussion on a political issue generally perceived as being the preserve of experts and fulfilled a social function by airing a broader and more diverse range of citizen voices.

\section{Results}

It must be kept in mind that the coverage analysed for this study took place in the highly politicised context of a major political event (Geoghegan 2014). Journalists and the organisations they worked for were subjected to political pressure from every angle during this period and John Robertson's assertions that the media had done a poor job of covering the first year of the referendum campaign had an enormous impact on public opinion. Given this atmosphere, professionals working for broadcasting corporations-particularly the BBC and STV-were reluctant to talk. While the tension surrounding the referendum made research on the topic more difficult, it also revealed a lot about the pressures that public service broadcasters are forced to deal with in highly partisan and polarised political situations.

Given their credibility with audiences, public service media outlets can make a big difference in how political issues are perceived. How, then, did an elitist institution like the BBC cover a political situation that could lead to the alteration of the existing order and in which public opinion would decide the final outcome? That is, the generally positive public attitude towards audience interaction with public media programmes aside, what happens in very specific contexts in which the status quo 
is challenged or under pressure? Public service broadcasting networks tend to be elitist institutions. How does this institutional elitism play out during potentially game-changing political events and processes that require public participation?

\subsection{Political Experts vs. Citizens Experience}

The phone-in show is generally considered a populist format best suited for addressing soft news topics. Elitist media organisations cling to a deeply rooted perception that political affairs should be discussed by expert commentators on news and current affairs programmes rather than by average citizens participating in phone-in shows. As Gerry Hassan has aptly noted, "professional and institutional elites have dominated public life" (Hassan 2014) and "one of the consequences of this state of affairs has been the development of a very weak, narrow public voice in society" (Hassan 2014). BBC Scotland has traditionally been viewed as an elitist broadcaster. For most of its history, Radio Scotland has offered programming primarily meant to appeal to what is referred to in the UK as an ABC1 audience, which is to say opinion makers, high earners and liberal professionals.

Although some editors at BBC Scotland feel the organisation has broadened its outlook over the past few years, few intellectuals have upgraded their generally low opinion of phone-in programmes. According to Radio Scotland's present editor of topical programmes, the network has traditionally had a snobbish attitude towards the format. "We didn't really want to do that", he admits, "because that was not really high enough quality for Radio Scotland" (Paterson 2014). Phone-in shows in Scotland and the UK have generally been devoted to sports. The format has always worked for football because nothing anyone talks about during a football phone-in really matters or threatens the existence of a powerful institution. However, it had never occurred to anyone to invite listeners to discuss more important matters on the air. The BBC was comfortable with sports phone-ins but did not consider the format suitable for other subjects such as politics. The prevailing mindset was that politics should be left to the experts. Paterson notes that more and more phone-ins are finding their way onto BBC schedules, not so much for their capacity to foster interaction, but rather because they are popular with audiences and cheap to produce. He sees a logical connection between ongoing budget cuts and a growing interest in the format. Morning Call is the only phone-in radio programme in Scotland not devoted to sports. The only programme that could be considered vaguely similar is Brian Taylor's Big Debate, a travelling, location-based debate show, structured along the lines of BBC television's Question Time, which is produced before live audiences and does not accept phone calls from listeners. Morning Call is therefore in a unique position to give people a voice on topics of public interest. "I think it [the people's voice] has become stronger on Radio Scotland and I think the daily Morning Call provides quite a unique opportunity for that", Paterson asserted during his interview with researchers. "The programme has around 340,000 people listening to it every week" (Paterson 2014).

No programme aired by Radio Scotland, not even Morning Call, contains what could be construed as a power-sharing component. Radio Scotland retains ultimate editorial control over everything it produces in line with sector regulation and the standards on which its broadcasting licence depends.

\subsection{The Potential of the Human Angle on Success}

The freelance journalists interviewed for this study agreed that the format of BBC Scotland's Newsnight was awkward and did little to spark listener interest in the debates it offered or foster public engagement on current issues. The editor of Morning Call informed us that his show now rivals the network's more traditional news programmes in terms of audience size.

The programme's success raises the question as to whether other radio programmes might do well to adopt a similar style and format. Generally speaking, the BBC's news programmes have always tended to focus on institutions rather than people. News shows have covered global world politics and parliamentary activity whereas phone-ins have covered human-interest stories and been used to address hard news from a more human angle. 


\subsection{Referendum: A Magnet Topic}

According to Paterson, listener calls increased 50\% on days when the programme focused on referendum-related topics. This indicates that given the opportunity to express their opinions about important issues in a non-stressful environment in which they run a low risk of being judged, people are much more inclined to become involved in the political process. The bigger question is who plays the determining role in getting people to speak out and act publicly. Is it social movements that convince people to make their voices heard in the media and thus participate in civic debate, or is it the media that boosts people's willingness to become involved in civic affairs by giving them a public voice? Whichever is the case, the main challenge facing social campaigners and the media alike during the run-up to the Scottish referendum was engaging undecided voters.

\subsection{Why Call? Reacting or Sharing Experiences}

What specifically prompts people to participate in phone-in programmes? It is generally thought that most do it out an urge to react to something someone else has said on the air or to express an opinion on a subject they are passionate about. Interactions on Morning Call fall into two basic categories. One takes the form of the traditional head-to-head debate in which a subject is discussed from two opposing angles. The other entails sharing personal experiences (rather than expertise) related to topics of social interest such as depression or care for the elderly. People who enter into the latter type of conversation are motivated by the notion that what they say might be useful to other listeners. Those who engage in the former type of interaction are usually interested in expressing a partisan opinion on a topic such as the independence referendum. Emotional debates on passionate topics generate far more interaction than personal anecdotes. The editor of Morning Call admitted during his interview with the researchers involved in this study, "I don't think anybody tunes in with the thought that they are going to change something" (Paterson 2014).

Media outlets seeking to encourage audiences to express personal viewpoints on political issues need to formulate the questions they put to them carefully, ensuring that they are not only catchy but also relate to what audiences want and need to know the most. Broadcasters in the UK, for example, should take into account the fact mentioned earlier in this paper that only $32 \%$ of British citizens perceive a distinction between the UK parliament and government. The BBC's tendency to place an overwhelming priority on value-added intellectual debate reinforces a contagious notion that ordinary people's opinions do not matter. Comments posted on BBC Scotland social media accounts critical of other callers' ignorance of the 2014 referendum and other complex issues such as "that person doesn't know what she's talking about" may dissuade interested people from contributing to civic debate. We nevertheless argue that such voices deserve to be heard on the radio because they provide an authentic reflection of society as a whole. Callers who cannot name the current Lord Chancellor off the cuff, may not have the clearest understanding of the UK's relationship with the EU or have at best a shaky grasp of Scottish history are certainly not alone. This is a reality the media needs to acknowledge and that their programming should reflect. Even if only $10 \%$ of the Scottish public was truly interested in debating the fine points of the independence issue, at least another $50 \%$ could have been engaged as well if questions had been framed from the right angle.

Phone-in programmes like Morning Call provide testimonies of human experience that can often be more useful to policymakers than answers to direct questions. Let us consider, for example, the issue of food served in Scotland's hospitals. People are apt to respond quite differently to the questions "How would you change hospital menus?" and "What has been your own experience with hospital food?" Programmes like Morning Call frame topics from a non-elitist perspective and provide a public space in which people are able to share their personal experiences with others. What they do not do, however, is involve audiences in content production and debate at a structural level. Public service broadcasters, like their private counterparts, decide what topics are discussed and what voices are heard. 


\section{Discussion and Conclusions}

This study has focused on a particular BBC radio phone-in show and its approach to civic debate on perhaps the most heated issue it has dealt with to date-whether Scotland should or should not remain part of the United Kingdom. The findings indicate that although this programme retained ultimate control of audience interaction, it did allow many average people to voice their opinions on the topic. The fact that Morning Call received many more phone-ins than usual whenever the referendum was the topic of the day is significant given the degree to which the success of such shows depends upon the audience participation they generate. It is also evident that Morning Call contributed to the debate on this issue. BBC Scotland does not give its listeners an agenda-setting or co-production role and, in fact, lacks the structure to do so. Such organisations nevertheless provide an unintimidating platform for audiences to say what they think about issues generally considered to be beyond their ken.

Mark Moore has observed that the creation of public value hinges upon cooperation between public entities and society (Moore 1995, p. 56). Phone-in shows create public value by offering average citizens an opportunity to express their opinions about matters of political weight normally considered to be the exclusive preserve of professional experts in the context of high-profile programmes targeting nationwide audiences. As Grünangerl, Trappel and Wenzel have pointed out, the BBC stands out among the public service broadcasters that have embraced the idea that "in order to create public value for society, it seems necessary to collaborate and cooperate with citizens. This implies the consideration of people as citizens rather than consumers" (Grünangerl et al. 2012).

We assert that the performance and societal value of public service media should be assessed on a case-by-case basis rather than by means of a standard yardstick. The form citizen involvement takes will ultimately vary from one PSB to another according to the role each plays in informing the public and the necessities of specific audiences and society in general. Although the organisational structures and approaches they adopt may be different, public service radio broadcasters and community radio broadcasters both have important roles to play in public value creation. The researchers involved in this study agree with the authors of a recently published paper comparing public media and community media (Grünangerl et al. 2012) that community media organisations would do well to define their performance in terms of civic rather than public value.

Programmes allowing average people to share personal experiences related to issues of public interest can boost civic engagement. However, a basic prerequisite for both this kind of programme and civic engagement in general is a well-informed audience, and that is where news programmes produced by major public service media networks fit into the picture.

Although it is easy to dismiss phone-in shows, such programmes can nevertheless make an important difference in exceptional instances in which they constitute the only programme aired by a public broadcasting network that offers average citizens a chance to contribute to the public debate on an important political issue in an atmosphere in which intimidating experts are not controlling the discourse. Programmes like Morning Call foster political engagement by framing important issues from the perspective of human experience. What motivates people to participate in a public political debate? It appears to be an open invitation to express their views from the perspective of personal experience in a non-judgemental environment in which they run no risk of being belittled. This suggests that we might do better to think less about the media as institutions and more about communication as a process.

Author Contributions: Conceptualization, I.A.-O., A.L.-U. and S.P.-F.; methodology, I.A.-O. and A.L.-U.; formal analysis, I.A.-O.; investigation, I.A.-O. and A.L.-U.; resources, I.A.-O., A.L.-U. and S.P.-F.; writing-original draft preparation, I.A.-O.; writing-review and editing, A.L.-U. and S.P.-F.; supervision, S.P.-F.; funding acquisition, A.L.-U. and S.P.-F.

Funding: This study was carried out within the Consolidated Research Group 'Gureiker' (A) (IT1112-16), funded by the Basque Government.

Conflicts of Interest: The authors declare no conflict of interest. Individuals who have contributed original information to this article agree to be identified by name in relation to this project. 


\section{References}

BBC Trust. 2014. Annual Report and Accounts 2013-14. London: BBC.

Blain, Neil, and David Hutchinson. 2016. Scotland's Referendum and the Media: National and International Perspectives. Edinburgh: Edinburgh University Press.

Blumler, Jay G., and Dennis Kavanagh. 2000. The third age of political communication: Influences and features. Political Communication 16: 209-30. [CrossRef]

Carpentier, Nico. 2012. Maximalist and minimalist definitions of participation. Paper presented at the Institutionen för Kommunikation och Medier Media and Participation Conference, Lund, Sweden, March 29.

Carpentier, Nico. 2014. Fuck the clowns from Grease!! Fantasies of participation and agency in the YouTube comments on a Cypriot problem documentary. Information, Communication \& Society 17: 1001-16.

Couldry, Nick, Sonia Livingstone, and Tim Markham. 2007. Connection or disconnection?: Tracking the mediated public sphere in everyday life. In Media and Public Spheres. London: Palgrave Macmillan.

Dahlgren, Peter. 2005. The Internet, public spheres, and political communication: Dispersion and deliberation. Political Communication 22: 147-62. [CrossRef]

Dekavalla, Marina. 2016. Framing referendum campaigns: The 2014 Scottish independence referendum in the press. Media, Culture E Society 38: 793-810.

Geoghegan, Peter. 2014. The People's Referendum: Why Scotland Will Never Be the Same Again. Edinburgh: Lauth Press Ltd.

Geoghegan, Peter. 2014. Personal interview, Glasgow, April 10.

Grünangerl, Manuela, Josef Trappel, and Corinna Wenzel. 2012. Public value and participation of civil society-A case for public service or community media? Kommunikation Medien 1: 1-32.

Hansard Society. 2011. Connecting Citizens to Parliament: How Parliament Can Engage More Effectively with Hard to Reach Groups. London: The Hansard Society.

Hansard Society. 2012. Audit of Political Engagement 9. London: The Hansard Society.

Hansard Society. 2013. Audit of Political Engagement 10. London: The Hansard Society.

Hassan, Gerry. 2014. Caledonian Dreaming: The Quest for a Different Scotland. Edinburgh: Luath Press Ltd., volume 1.

Hassan, Gerry. 2014. Personal interview, Glasgow, March 3.

Hutchby, Ian. 2013. Confrontation Talk: Arguments, Asymmetries, and Power on Talk Radio. London: Routledge.

Lachlan, Kenneth A. 2016. BIRGing, CORFing, and Twitter Activity Following a Political Referendum: Examining Social Media Activity Concerning the 2014 Scottish Independence Vote. Communication Research Reports 33: 217-22. [CrossRef]

Lewis, Seth. 2012. The Tension Between Professional Control and Open Participation. Information, Communication $\mathcal{E}$ Society 15: 836-66.

Livingstone, Sonia. 2004. The challenge of changing audiences: Or, what is the audience researcher to do in the age of the Internet? European Journal of Communication 19: 75-86. [CrossRef]

Macnamara, Jim, Phyllis Sakinofsky, and Jenni Beattie. 2012. E-electoral engagement: How governments use social media to engage voters. Australian Journal of Political Science 47: 623-39. [CrossRef]

Moe, Hallvard. 2008. Dissemination and dialogue in the public sphere: A case for public service media online. Media Culture and Society 30: 319-36. [CrossRef]

Moore, Mark Harrison. 1995. Creating Public Value: Strategic Management in Government. Cambridge: Harvard University Press.

NatCen Social Research. 2013. Purpose Remit Survey Winter 2012-13. London: NatCen.

Ofcom. 2013. Public Perceptions of the Impartiality and Trustworthiness of the BBC, Data for Public Release. London: Ofcom.

Paterson, Colin. 2014. Personal interview, Glasgow, May 22.

Prior, Markus. 2007. Post-Broadcast Democracy: How Media Choice Increases Inequality in Political Involvement and Polarizes Elections. Cambridge: Cambridge University Press.

Robertson, John. 2014. Fairness in the First Year? BBC and ITV Coverage of the Scottish Referendum. Scotland: Creative Futures Institute, School of Creative and Cultural Industries, University of the West of Scotland.

Ross, Karen. 2004. Political talk radio and democratic participation: Caller perspectives on Election Call. Media, Culture E Society 26: 785-801. 
Scottish Broadcasting Commission. 2008. Platform for Success: Final Report of the Scottish Broadcasting Commission. Edinburgh: Scottish Broadcasting Commission.

Shephard, Mark Peter, and Stephen Quinlan. 2015. Social media and the Scottish independence referendum 2014: Events and the generation of enthusiasm for yes. In The Routledge Companion to Social Media and Politics. Oxford: Routledge, pp. 488-502.

Steensen, Steen. 2011. Online Journalism and the Promises of New Technology. A Critical Review and Look Ahead. Journalism Studies 12: 311-27. [CrossRef]

Warner, Benjamin R., Sarah Turner McGowen, and Joshua Hawthorne. 2012. Limbaugh's social media nightmare: Facebook and Twitter as spaces for political action. Journal of Radio $\mathcal{E}$ Audio Media 19: 257-75.

Wayne, Michael. 2016. Beneath the bias, the crisis: The press, the independent media and the Scottish referendum. International Journal of Media \& Cultural Politics 12: 323-40.

Williams, Andy, Claire Wardle, and Karin Wahl-Jorgensen. 2011. "Have they got news for us?" Audience revolution or business as usual at the BBC? Journalism Practice 5: 85-99. [CrossRef]

Witschge, Tamara. 2014. Passive accomplice or active disruptor: The role of audiences in the mediatization of politics. Journalism Practice 8: 342-56. [CrossRef]

(C) 2019 by the authors. Licensee MDPI, Basel, Switzerland. This article is an open access article distributed under the terms and conditions of the Creative Commons Attribution (CC BY) license (http://creativecommons.org/licenses/by/4.0/). 